\title{
An Assessment of Dental Anxiety in Patients Before and After Scaling and Polishing Procedures
}

\author{
Sai S. Sreeja ${ }^{1}$ Rahul Bhandary ${ }^{1} \quad$ Amitha Ramesh Bhat $^{1}$ Nina Shenoy ${ }^{1}$ \\ ${ }^{1}$ Department of Periodontics, AB Shetty Memorial institute of Dental \\ Sciences, Nitte (Deemed to be University), Derlakatte, Mangalore, \\ Karnataka, India

\begin{abstract}
Address for correspondence Rahul Bhandary, MDS, Department of Periodontics, AB Shetty Memorial institute of Dental Sciences, Nitte (Deemed to be University), Derlakatte, Mangalore 575018, Karnataka, India (e-mail: drrahulbhandary@nitte.edu.in).
\end{abstract}

J Health Allied Sci ${ }^{\mathrm{NU}}$ 2022;12:243-246.

\section{Abstract \\ Keywords \\ - dental apprehension \\ - gender difference \\ - oral hygiene}

Introduction As of now, there are not many investigations about the improvement of dental apprehension and dental participation in various populations over time. This investigation includes an examination of emotional appraisals of levels of dental apprehension in patients selected at the $A B$ Shetty Memorial Institute of Dental Sciences. The investigation also aimed to discover the causes of dental apprehension as well as the effect of sexuality on the distinguished dental apprehension.

Materials and Methods The level of dental apprehension was assessed using questionnaires that included 15 questions before and after the scaling and polishing procedures for 78 patients. The typical features were drawn such as gender, age, and oral hygiene habits. The data analysis was analyzed using paired $t$-test or Wilcoxon signed rank test to assess pre- and postanxiety levels.

Results A total of 78 responses were collected, resulting in a participation rate of $100 \%$. Despite the fact that women had significantly higher overall dental apprehension levels compared with men, the discrepancy among the two genders was substantial and could be clarified.

Conclusion Dental fear was common in females, especially among those with dental problems, and a larger degree of dental fear can contribute to periodontal disease.

\section{Introduction}

Dental apprehension is a salient, if not the primary, component of concern for patients in the waiting room. Apprehension in dentistry is more distinct than general anxiety; it is a reaction of the patient to the stress that is relevant to the dental condition. ${ }^{1}$ If the dentist is conscious of his patient's level of anxiety, he might not only be warned about the actions of the patient but will also be able to take up steps to reduce the distress during the course of the procedure. Thus, extremely nervous patients may respond differently to dental care than those who are comparatively less apprehensive. ${ }^{2}$

published online

November 5, 2021
DOI https://doi.org/ 10.1055/s-0041-1736453. ISSN 2582-4287.
Dental apprehension is distinguished from fear, as it represents a mixture of biochemical shifts in the body and the personal state of the patient's past, evocation, and the state of culture. $^{3}$

The causative factors that influence dental anxiety include negative knowledge, experiencing any bad events, and negative outcomes. Dental anxiety, meanwhile, was seen as a dynamic mechanism with both external and internal variables interacting simultaneously. Some of the factors that are associated with exogenous components are traumatic events and negative experiences, whereas endogenous components were more likely to be genetically and physiologically (c) 2021. Nitte (Deemed to be University). All rights reserved. This is an open access article published by Thieme under the terms of the Creative Commons Attribution-NonDerivative-NonCommercial-License, permitting copying and reproduction so long as the original work is given appropriate credit. Contents may not be used for commercial purposes, or adapted, remixed, transformed or built upon. (https://creativecommons.org/ licenses/by-nc-nd/4.0/)

Thieme Medical and Scientific Publishers Pvt. Ltd., A-12, 2nd Floor, Sector 2, Noida-201301 UP, India 
determined. ${ }^{4}$ It was generally known that the most of patients with dental anxiety had painful experiences during the treatment. During periodontal scaling/nonsurgical periodontal care, a high degree of pretreatment fear was reported for pain experience. ${ }^{5}$

Several studies have stated that elevated levels of dental anxiety have been correlated with periodontal therapy. In patients with dental anxiety and fear, it could affect their oral health treatment and this simultaneously would affect their maintenance of oral health. The perception of discomfort during scaling and polishing procedures may also discourage patients without periodontitis. ${ }^{6}$

Periodontal disease, which is one of the most significant oral disease, is highly prevalent worldwide and, in many countries, is a major public health issue. ${ }^{7}$ Periodontal disease prevalence has been reported to range from 20 to $50 \%$ worldwide. ${ }^{8}$ Periodontitis accounts for approximately 15 to $20 \%$ of tooth loss at the age of 35 to 44 years, according to the World Health Organization (WHO). Nevertheless, there is a lack of assessment of dental anxiety in patients before and after scaling and polishing procedures. The current research used validated questionnaires to measure the frequency of dental apprehension in patients before and after scaling and polishing procedures to determine whether dental apprehension has an effect on overall oral hygiene maintenance.

\section{Materials and Methods}

\section{Study Design and Participants}

A cross-sectional study was performed from January to March 2021, with a sample of 78 patients in the AB Shetty Memorial Institute of Dental Sciences. The inclusion criteria for participants were those with an age group of 18 years and above. The exclusion criteria were participants who were under 18 years of age and patients who refuse to cooperate. The participants included both males and females. The sample size was calculated to be 78 , including 39 males and 39 females. Data was collected using a convenient sampling process, and the distribution of responses was presented as frequency and percentages. Identification numbers were randomly assigned to each questionnaire to ensure the integrity of answers and easy identification of the questionnaires by participants. Written consent was obtained from each patient before conducting the survey.

\section{Data Collection and Questionnaires}

In this research, a self-assessed standardized questionnaire with a set of closed-ended questions was used. The questionnaire consisted of two segments with a complete set of 15 questions. The first segment included the questions before the cleaning and polishing procedures, whereas the second segment included the questions after the cleaning and polishing procedures. The questionnaires were validated. It took approximately 6 to 7 minutes to complete each questionnaire.

Aside from the questionnaire, general details included dental visits (regular or irregular) and sociodemographic characteristics such as gender, age, education, marital status, smoking, and alcohol use.
Table 1 Demographic data

\begin{tabular}{|l|l|l|l|}
\hline Gender & Age group & No. & $\%$ \\
\hline Males & $18-40$ & 39 & $50.0 \%$ \\
\hline Females & $18-40$ & 39 & $50.0 \%$ \\
\hline Total & & 78 & $100 \%$ \\
\hline
\end{tabular}

\section{Data Analysis}

For each variable, the mean and standard deviations were calculated. Data will be analyzed using paired-t test or Wilcoxon's signed rank test to assess pre and post anxiety levels. P-value $<0.05$ considered statistically significant. Statistical analyses of data were done using SPSS version 20.

\section{Results}

A total of 78 patients have taken part in the survey at $A B$ Shetty Memorial Institute of Dental Sciences, Mangalore. The majority of the respondents $(n=78)$ were between the ages of 18 to 40 years. Out of the 78 patients, the survey included 39 males (50.0\%) and 39 females (50.0\%) (-Table 1).

The responses with frequency (percentage) and gender for each question have been reported in the - Table 2 .

- Table 2 represents the number and frequency or percentage with gender for each question. The local anesthetic injection in the gums received the highest anxiety score (Q5 ). The next highest anxiety-producing question was when gums were being assessed with a probe (Q-8). The results of the analysis have proven the relationship between dental apprehension and gender. The incidence of dental apprehension was notably higher in females $(p<0.05)$.

\section{Discussion}

Apprehension is a typical reason for people postponing seeking oral care, because apprehension is a common feeling among humans, which occurs in a variety of contexts, including dental settings. ${ }^{9}$

Apprehension about going to the dentist can be prompted by the practitioner. Apart from human variables, there are other aspects relating to the environment which might cause apprehension in humans. ${ }^{10,11}$ Knowing about a patient's apprehension prior to treatment will help the clinician to be conscious of what to expect from the patient and take preventive measures to make the patient feel less apprehensive. ${ }^{12}$

In this study, 78 patients were examined before and after scaling and polishing procedures to see if there was an association between gender and dental fear. A set of validated questions were asked pre and postcleaning and polishing procedures to the patient to predict their anxiety levels. It was seen that females have higher levels of dental apprehension when compared with males. Furthermore, the consequences of dental apprehension are more severe in women than in men, because women are far more likely to stop receiving dental treatment in terms of their anxiety, putting their health at risk. ${ }^{13-16}$ Akshaya et al conducted research to 
Table 2 Number and frequency (percentage) with gender for each question

\begin{tabular}{|c|c|c|c|c|c|c|c|c|c|c|c|}
\hline & \multirow[t]{2}{*}{ Gender } & \multicolumn{2}{|c|}{ Not anxious } & \multicolumn{2}{|c|}{ Slightly anxious } & \multicolumn{2}{|c|}{ Fairly anxious } & \multicolumn{2}{|c|}{ Very anxious } & \multicolumn{2}{|c|}{$\begin{array}{l}\text { Extremely } \\
\text { anxious }\end{array}$} \\
\hline & & $n$ & $\%$ & $n$ & $\%$ & $n$ & $\%$ & $n$ & $\%$ & $n$ & $\%$ \\
\hline \multirow[t]{2}{*}{ Q-1 } & Male & 24 & 61.5 & 11 & 28.2 & 3 & 7.7 & 1 & 2.6 & - & - \\
\hline & Female & 17 & 43.6 & 16 & 41.0 & 4 & 10.3 & 2 & 5.1 & - & - \\
\hline \multirow[t]{2}{*}{ Q-2 } & Male & 25 & 64.1 & 11 & 28.2 & 1 & 2.6 & 2 & 5.1 & - & - \\
\hline & Female & 27 & 69.2 & 6 & 21.8 & 3 & 7.7 & 3 & 7.7 & - & - \\
\hline \multirow[t]{2}{*}{ Q-3 } & Male & 30 & 76.9 & 8 & 20.5 & 1 & 2.6 & 0 & 0.0 & - & - \\
\hline & Female & 20 & 51.3 & 14 & 35.9 & 3 & 7.7 & 2 & 5.1 & - & - \\
\hline \multirow[t]{2}{*}{ Q-4 } & Male & 10 & 25.6 & 15 & 38.5 & 14 & 35.9 & 0 & 0.0 & - & - \\
\hline & Female & 5 & 12.8 & 14 & 35.9 & 15 & 38.5 & 5 & 12.8 & - & - \\
\hline \multirow[t]{2}{*}{ Q-5 } & Male & 9 & 23.1 & 9 & 23.1 & 12 & 30.8 & 7 & 17.9 & 2 & 5.1 \\
\hline & Female & 5 & 12.8 & 7 & 17.9 & 8 & 20.5 & 16 & 41.0 & 3 & 7.7 \\
\hline \multirow[t]{2}{*}{ Q-6 } & Male & 8 & 20.5 & 9 & 23.1 & 20 & 51.3 & 2 & 5.1 & - & - \\
\hline & Female & 8 & 20.5 & 13 & 33.3 & 14 & 35.9 & 4 & 10.3 & - & - \\
\hline \multirow[t]{2}{*}{ Q-7 } & Male & 18 & 46.2 & 14 & 35.9 & 5 & 12.8 & 2 & 5.1 & - & - \\
\hline & Female & 13 & 33.3 & 20 & 51.3 & 5 & 12.8 & 1 & 2.6 & - & - \\
\hline \multirow[t]{2}{*}{ Q-8 } & Male & 13 & 33.3 & 13 & 33.3 & 10 & 25.6 & 2 & 5.1 & 1 & 2.6 \\
\hline & Female & 11 & 28.2 & 11 & 28.2 & 8 & 20.5 & 9 & 23.1 & 0 & 0.0 \\
\hline \multirow[t]{2}{*}{ Q-9 } & Male & 28 & 71.8 & 8 & 20.5 & 2 & 5.1 & 1 & 2.6 & - & - \\
\hline & Female & 26 & 66.7 & 11 & 28.2 & 1 & 2.6 & 1 & 2.6 & - & - \\
\hline \multirow[t]{2}{*}{ Q-10 } & Male & 9 & 23.1 & 21 & 53.8 & 7 & 17.9 & 2 & 5.1 & 0 & 0.0 \\
\hline & Female & 11 & 28.2 & 13 & 33.3 & 9 & 23.1 & 5 & 12.8 & 1 & 2.6 \\
\hline \multirow[t]{2}{*}{ Q-11 } & Male & 29 & 74.4 & 10 & 25.6 & 0 & 0.0 & - & - & - & - \\
\hline & Female & 28 & 71.8 & 10 & 25.6 & 1 & 2.6 & - & - & - & - \\
\hline \multirow[t]{2}{*}{ Q-12 } & Male & 24 & 61.5 & 15 & 38.5 & 0 & 0.0 & 0 & 0.0 & - & - \\
\hline & Female & 23 & 59.0 & 11 & 28.2 & 4 & 10 & 1 & 2.6 & - & - \\
\hline \multirow[t]{2}{*}{ Q-13 } & Male & 5 & 12.8 & 13 & 33.3 & 17 & 4.6 & 4 & 10.3 & - & - \\
\hline & Female & 4 & 10.3 & 8 & 20.5 & 15 & 8.5 & 12 & 30.8 & - & - \\
\hline \multirow[t]{2}{*}{ Q-14 } & Male & 9 & 23.1 & 19 & 48.7 & 11 & 28.2 & 0 & 0.0 & 0 & 0.0 \\
\hline & Female & 3 & 7.7 & 16 & 41.0 & 12 & 30.8 & 7 & 17.9 & 1 & 2.6 \\
\hline \multirow[t]{2}{*}{ Q-15 } & Male & 36 & 92.3 & 3 & 7.7 & 0 & 0.0 & - & - & - & - \\
\hline & Female & 30 & 76.9 & 8 & 20.5 & 1 & 2.6 & - & - & - & - \\
\hline
\end{tabular}

assess dental anxiety and dread of dental care among patients who visited Saveetha Dental College and stated that dental apprehension and dread is more frequent in women compared with men. ${ }^{17}$ Sukumaran et al in 2021 conducted research on the prevalence and impact of dental anxiety among adult New Zealanders and stated that the apprehension was more frequent in women who belong to the age bracket of 18 to 54 years; additionally, people with dental phobia showed significantly increased levels of oral health-related quality of life ratings. ${ }^{18}$ The ability of men and women to tolerate discomfort differs, according to research findings. Women, on the other hand, were more likely than men to have a low pain tolerance. ${ }^{19,20}$ Also, it was determined that even after the therapy, females continue to memorize their negative episodes profoundly. ${ }^{21}$ Hence, the dissimilarity among the tolerance levels can be another factor for the disparity. When opposed to older adults, teenagers and kids tend to have minor engagement with dental apparatus. As a result, terror of uncertainty develops. Hence, through this kind of unidentified dread, teenagers tend to be susceptible to be apprehensive when it comes to dental operations. ${ }^{21}$

Infrequent visits to the dentist, long waits in the dental office, past painful dental encounters, discomfort during dental care, the type of treatment received, and how intrusive the treatment is may all lead to high levels of dental apprehension in females. ${ }^{22}$ Patients' apprehension can be compounded by a lack of dental health education, resulting in impaired patient treatment outcomes and behaviors. This 
data can be used to develop the best methods for dealing with patient apprehension. When dealing with patients who have dental anxiety, calm, compassionate, skilled, sensitive, and more supportive methods are essential for a good dental treatment. The first appointment is more critical for patients with dental apprehension to avoid their ignorance of dental treatment. They should be managed in a more courteous and sensitive way. ${ }^{23}$ Moreover, it has been proposed that good dental care and maintenance are critical for good overall hygiene and the avoidance of gum diseases.

\section{Conclusion}

There was a higher prevalence of dental apprehension in females when compared with males. Dental visits and oral hygiene habits can influence dental apprehension, and a high level of dental fear can result in negative periodontal health.

\section{Conflict of Interest}

None declared.

\section{References}

1 Amir A, Kamate S, Gupta P, Gupta A, Singh J, Singh S. Assessment of dental anxiety using MDAS (Modified Dental Anxiety Scale) among students in Bareilly City-A cross sectional study. Int J Contemp Med Res. 2018;5(03):5-7

2 Corah NL, Gale EN, Illig SJ. Assessment of a dental anxiety scale. J Am Dent Assoc 1978;97(05):816-819

3 Lewis G. DSM-IV. Diagnostic and Statistical Manual of Mental Disorders, 4th ed. By the American Psychiatric Association (pp. 886; £34.95.) APA: Washington, DC.1994. Psychological Medicine 1996;26(03):651-652

4 Liu Y, Huang X, Yan Y, Lin H, Zhang J, Xuan D. Dental fear and its possible relationship with periodontal status in Chinese adults: a preliminary study. BMC Oral Health 2015;15(01):18

5 Guzeldemir E, Toygar HU, Cilasun U. Pain perception and anxiety during scaling in periodontally healthy subjects. J Periodontol 2008;79(12):2247-2255

6 Heins PJ, Karpinia KA, Maruniak JW, Moorhead JE, Gibbs CH. Pain threshold values during periodontal probing: assessment of maxillary incisor and molar sites. J Periodontol 1998;69(07):812-818

7 Bratthall D, Petersen PE, Stjernsward JR, Brown LJ. Oral and craniofacial diseases and disorders. In: Jamison DT, Breman JG, Measham AR, Alleyne G, Claeson M, Evans DB, Jha P, Mills A, eds. Disease Control Priorities in Developing Countries. 2nd ed. Washington (DC): Musgrove P; 2006
8 Sanz M. European workshop in periodontal health and cardiovascular disease. Eur Heart J Suppl 2010;12(Suppl B):B2

9 Giri J, Pokharel PR, Gyawali R, Bhattarai B. Translation and validation of modified dental anxiety scale: the Nepali version. International Scholarly Research Notice 2017;2017:5

10 Minja IK, Kahabuka FK. Dental Anxiety and its Consequences to Oral Health Care Attendance and Delivery. Anxiety Disord-from Child to Adulthood London, UK: IntechOpen; 2019

11 Beaton L, Freeman R, Humphris G. Why are people afraid of the dentist? Observations and explanations. Med Princ Pract 2014;23 (04):295-301

12 Musalam K, Sohal KS, Owibingire SS, Kileo B. Magnitude and determinants of dental anxiety among adult patients attending public dental clinics in Dar-Es-Salaam, Tanzania. Int J Dent 2021; 2021:9965204

13 Saatchi M, Abtahi M, Mohammadi G, Mirdamadi M, Binandeh ES. The prevalence of dental anxiety and fear in patients referred to Isfahan Dental School, Iran. Dent Res J (Isfahan) 2015;12(03): 248-253

14 Alhamed SA, Halawani RT, Ahmed HA, et al. Dental anxiety among adult patients attending public dental clinics in jeddah, Saudi arabia. Curr Sci Int 2019;8(02):363-367

15 Murad MH, Ingle NA, Assery MK. Evaluating factors associated with fear and anxiety to dental treatment-A systematic review. J Family Med Prim Care 2020;9(09):4530-4535

16 Sinha E, Rekha R, Nagashree S. Anxiety of dental treatment among patients visiting primary health centers. Journal of Indian Association of Public Health Dentistry 2019;17(03):235

17 Akshaya R, Preejitha VB, Brundha MP. A survey study of genderrelated anxiety and fear on dental care among the patients visiting Saveetha Dental College and Hospital. Drug Invention Today. 2020;13(02):231-234

18 Sukumaran I, Taylor S, Thomson WM. The prevalence and impact of dental anxiety among adult New Zealanders. Int Dent J 2020;71 (02):122-126

19 Eltumi HG, Tashani OA. Effect of age, sex and gender on pain sensitivity: A narrative review. Open Pain J 2017;10:44-55

20 Appukuttan D, Datchnamurthy M, Deborah SP, Hirudayaraj GJ, Tadepalli A, Victor DJ. Reliability and validity of the Tamil version of modified dental anxiety scale. J Oral Sci 2012;54 (04):313-320

21 Bano S, Ahmad SA, Vyas K. Exploring dental anxiety among male and female across adolescents, young adults, and middle adults. Journal of Dental Research and Review. 2021;8(02): 107

22 Biggs QM, Kelly KS, Toney JD. The effects of deep diaphragmatic breathing and focused attention on dental anxiety in a private practice setting. J Dent Hyg 2003;77(02):105-113

23 Freeman R. A psychodynamic theory for dental phobia. Br Dent J 1998;184(04):170-172 